\title{
Possible role of Escherichia coli in propagation and perpetuation of chronic inflammation in ulcerative colitis
}

\author{
Magdalena Pilarczyk-Zurek , Agnieszka Chmielarczyk ${ }^{1}$, Tomasz Gosiewski ${ }^{1}$, Anna Tomusiak , Pawel Adamski ,
} Malgorzata Zwolinska-Wcislo ${ }^{3}$, Tomasz Mach ${ }^{3}$, Piotr B Heczko ${ }^{1}$ and Magdalena Strus ${ }^{{ }^{*}}$

\begin{abstract}
Background: This study investigated a possible role of Escherichia coli in propagation and perpetuation of the chronic inflammation in ulcerative colitis (UC). The lesions of UC are located superficially on the rectal and/or colonic mucosa. It is suggested that the commensal bacteria of the digestive tract may play a role in the pathogenesis of UC. Several studies have demonstrated proliferation of E. coli in the gut of UC patients. An increase in the number of $E$. coli in the inflamed tissue is most probably related to the abundance of iron ions produced by the bacteria.
\end{abstract}

Methods: Colon mucosal biopsies were collected from 30 patients with acute-phase UC, both from tissues with inflammatory changes $(n=30)$ and unchanged tissue with no inflammatory changes $(n=30)$ from the same patient. Biopsies were also taken from 16 patients with irritable bowel syndrome diarrhea who comprised the control group. Quantitative and qualitative analysis of the biopsy specimens was performed using culture methods and real-time polymerase chain reaction (PCR). Genotyping of the E. coli isolates was done using pulsed-field gel electrophoresis. Multiplex PCR was used to compare the E. coli strains for the presence of genes responsible for synthesis of iron acquisition proteins: iroN, iutA, iha, ireA, chuA, and hlyA.

Results: We demonstrated that there was a significant increase in the number of $E$. coli at the sites of inflammation in patients with UC compared to the control group $(P=0.031)$. Comparative analysis of the restriction patterns of E. coli isolated from inflammatory and unchanged tissues showed that the local inflammatory changes did not promote specific $E$. coli strains. There was a significant difference in the frequency of the iroN gene in $E$. coli isolated from patients with UC as compared to the control group.

Conclusions: The increase in the numbers of $E$. coli in the inflammatory tissues is related to the presence of chuA and iutA genes, which facilitate iron acquisition during chronic intestinal inflammatory processes.

Keywords: Ulcerative colitis, Escherichia coli, Iron acquisition

\section{Background}

Ulcerative colitis (UC) is a chronic inflammatory disease and, like Crohn's disease, belongs to the inflammatory bowel diseases (IBDs) [1,2]. The lesions of UC are located superficially on the rectal and/or colonic mucosa. The clinical course of UC is most commonly composed of exacerbation with periodic remission [3]. Disease

\footnotetext{
* Correspondence: mbstrus@cyf-kr.edu.pl

${ }^{1}$ Department of Microbiology, Jagiellonian University Medical College, Czysta 18 Street, Cracow 31-121, Poland

Full list of author information is available at the end of the article
}

activity is assessed based on medical history, as well as endoscopic changes in the large intestine [4].

Initial studies on the microbiology of UC were directed toward determination of a single etiological agent responsible for the development of IBD. Particular attention was paid to bacteria such as Salmonella, Shigella, Campylobacter, Listeria and Mycobacterium and their possible role in the inflammatory processes in the gastrointestinal (GI) tract $[5,6]$. None of the studies showed any increase in the populations of the above bacteria in the course of the disease. Currently, it is suggested that commensal bacteria of the

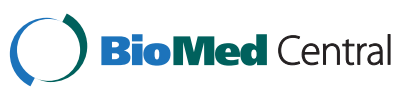


digestive tract may play a significant role in the pathogenesis of UC [2,7].

Several studies have demonstrated the proliferation of Escherichia coli in the gut of animal models and UC patients $[2,8,9]$. Studies performed on knockout mouse models $(129 / \mathrm{SvEv})$ have shown that chronic gut inflammation in $\mathrm{IL}-10^{-/-}$mice results in a reduction of gut microbiota diversity and a strong increase in intestinal E. coli [10].

The increase in the number of E. coli in the inflammatory tissue is most probably related to the abundance of iron ions available for siderophores produced by the bacteria [11]. Therefore, the significant increase in E. coli, but not their high virulence, may have an influence on the inflammatory process in the GI tract.

For E. coli that colonizes the human colon, it is important to have sufficient iron in the cells. In the process of acquiring iron ions, it is necessary for the cell to be able to produce transmembrane proteins that play a receptor role for siderophores that chelate iron ions. The receptor protein for hemin, which allows bacteria to use iron from heme, is coded by the chuA gene; synthesis of the receptor protein for phenol-derived siderophores is dependent on the iron gene; the protein that is an analog of the adhesion-forming part of the outer membrane is coded by the iha gene; and outer membrane proteins involved in binding other siderophores are coded by the iutA and ireA genes. Among E. coli strains isolated from patients suffering from diseases of the GI tract, strains that have the ability to lyse erythrocytes have been identified, with hemolysin $\alpha$ being the best characterized. Biosynthesis of the active form of the enzyme requires $h l y C$, hly $A, h l y B$ and $h l y D$ genes, post-translational modification, and secretion by protein translocators $[12,13]$.

There are reports that some E. coli genotypes are more likely associated with IBD than others [14]. In particular, E. coli strains belonging to phylogenetic groups associated with virulence genes and the ability to adhere to and invade host cells are more frequently isolated from IBD patients than from control subjects $[9,15]$. So far there has been no universal agreement as to which specific features are responsible for their dominance.

Studies on animal models [10] have not shown a clearcut correlation between increases in $E$. coli cell numbers and the severity of inflammation, which supports the assumption that high $E$. coli numbers are a consequence rather than a cause of disease. Furthermore, it has been shown that nonpathogenic E. coli strains even accelerate remission [16].

The aims of the present study were: (1) quantitative assessment of most important bacterial groups, with special emphasis on E. coli in patients with the active phase of UC, in sites of inflammatory changes and unchanged mucosa, as well as in the control group, based on culture methods and real-time polymerase chain reaction (PCR); (2) comparative genotyping of E. coli strains isolated from the same patients with active-phase UC from inflammatory and unchanged mucosa; and (3) comparison of the frequency of genes present, which are responsible for production of factors that facilitate iron ion acquisition (iroN, iutA, iha, ireA, chuA and hlyA).

\section{Methods}

\section{Study subjects}

The study material consisted of biopsies collected during colonoscopy from the colon mucosa of 30 patients with a diagnosis of acute-phase UC and from 16 patients with irritable bowel syndrome diarrhea who comprised the control group. The study was performed in the Clinic of Gastroenterology and Hepatology of the University Hospital in Cracow and in the Microbial Ecology Laboratory of the Chair of Microbiology, Jagiellonian University in 2008-2011, after approval by the Jagiellonian University Bioethical Committee (no. KBET/75/B from 15.11.2007). Informed consent was obtained from all patients participating in the study.

The average age of patients with UC was $42 \pm 11$ years, and the average disease duration was 5 years (1-23 years), with an average exacerbation rate of 1.5 /year. Activity of $\mathrm{UC}$ and exacerbation of endoscopic changes in the colon were based on the Mayo Clinic Disease Activity Index [4]. All subjects underwent the same type of preparation prior to colonoscopy, with oral sodium phosphate at a dose of $0.6-0.8 \mathrm{ml} / \mathrm{kg}$ (up to $45 \mathrm{ml}$ ) and bowel cleansing, consisting of four saline enemas. During colonoscopy, patients received intravenous sedation or general anesthesia, as required. Two biopsy specimens were collected from each patient with UC: one from the colonic mucosa with inflammatory changes (Sample A, $\mathrm{n}=30$ ); and the other from mucosa with no inflammatory signs (Sample B, $\mathrm{n}=30$ ). Inflammatory tissue was characterized during colonoscopy by disappearance of the vascular network, fragile mucosa with bleeding on contact, ulcerations, erosions, and sometimes pseudopolyps. The unaffected tissue showed normal mucosa with visible blood vessels, with no redness or mucosal depletion in the form of ulcers or erosions. In patients from the control group, no inflammatory changes were noted in the colon mucosa and only single biopsies were collected (Sample $C, n=16$ ). All tissues were subjected to histopathological assessment according to the Geboes scale [17]. The unaffected tissue from UC patients and mucosa from the control group received zero points according to the scale. The exclusion criteria were: diabetes, autoimmune disorders, severe systemic diseases, alcohol abuse, cow's milk allergy, and nonsteroidal anti-inflammatory drugs intake. All patients enrolled in the study received no antibiotics for at least 3 
months before colonoscopy. Patients with acute-phase UC received standard treatment with $3 \mathrm{~g} /$ day mesalamine.

\section{Qualitative and quantitative identification of bacterial species \\ Culture methods}

The collected biopsies were suspended in Schaedler broth (SAB; Difco, USA) with 10\% glycerol and stored at $-20^{\circ} \mathrm{C}$ for up to 1 week. The samples were transported to the microbiology laboratory on dry ice. The frozen samples were thawed, weighed, homogenized in $1 \mathrm{ml}$ $\mathrm{SAB}$, and quantitatively analyzed for the main bacterial constituents by culture on differential media in aerobic and anaerobic conditions [18]. All these manipulations were done aseptically in an anaerobic chamber (MACS; Don Whitley, Shipley, Yorks, UK) in an atmosphere of $\mathrm{N}(85 \%)+\mathrm{H}_{2}(10 \%)+\mathrm{CO}_{2}(5 \%)$. Homogenized samples were serially diluted with $\mathrm{SAB}$ and $100-\mu$ liquots were plated on the following media: McConkey Agar (Oxoid, Basingstoke, Hants, UK) for Enterobacteriaceae; Columbia Blood Agar (Difco) with 5\% sheep blood for streptococci; BBL Enterococcosel Agar (BD, Franklin Lakes, NJ, USA) for enterococci; MRS Agar (Oxoid) for lactobacilli and other lactic acid bacteria; BL Agar for bifidobacteria; and Wilkins-Chalgren Agar Base with supplements for Bacteroides [19]. The morphology of the colonies was analyzed under a magnifying glass and several colonies (7-10) of each morphological type were subcultured on appropriate aerobic and anaerobic media and Gram stained. After further incubation and culture purity checks, phenotypic identification was performed using commercial identification systems (API 20E, API 20A, API Staph, and API Strept; bioMerieux, Marcy l'Etoile, France; BBL Crystal ID System; BD). To verify speciation, all Gram-negative rods tested with API 20E were additionally analyzed with PCR with speciesspecific primers for E. coli [20]. The numbers of colonies of the bacterial groups and the sum of the cultured bacteria in the weighed tissue samples were converted into $1 \mathrm{~g}$ of the mass to make the quantitative comparisons among the patients.

\section{Real-time PCR}

Real-time PCR was used to verify the results obtained with culture methods. DNA extraction from all tissue samples was performed using the Genomic Mini Isolation Kit (A\&A Biotechnology, Poland), according to the manufacturer's recommendations, with our own modification. After lysis of the bacterial cells with lysozyme $(1 \mathrm{mg} / \mathrm{ml})$ and lysostaphin $(0.1 \mathrm{mg} / \mathrm{ml})$, samples were incubated at $37^{\circ} \mathrm{C}$ for $20 \mathrm{~min}$. Next, $200 \mu \mathrm{l} 75 \mathrm{mM} \mathrm{NaOH}$ $(50 \mathrm{mM})$ was added and samples were incubated at $95^{\circ} \mathrm{C}$ for $10 \mathrm{~min}$. After incubation, probes were microcentrifuged (12 $000 \mathrm{rpm}, 10 \mathrm{~min}$ ), supernatants were removed, and pelets were resuspended in $500 \mu$ l buffer suplemented with $\beta$-mercaptoethanol (Sigma). For each sample, lyticase was added $(0.1 \mathrm{mg} / \mathrm{ml})$. Probes were incubated at $37^{\circ} \mathrm{C}$ for at least $30 \mathrm{~min}$ and microcentrifuged (12 $000 \mathrm{rpm}, 10 \mathrm{~min}$ ). The next steps of DNA extraction were carried out according to A\&A Biotechnology's procedure.

To detect specific DNA sequences after extraction, fluorescently labeled probes and pairs of specific primers were used (Table 1). E. coli in the corresponding tissue samples was quantified by Real-Time PCR, as described previously [21]. A standard curve was prepared. DNA from given numbers of $E$. coli was added in serial dilutions from $10^{1}$ to $10^{8}$ cells to a series of PCRs. The reactions were carried out in a BioRad thermocycler, and the fluorescence was monitored throughout the reaction. The results are shown in Figure 1. A standard curve from these data is shown in Figure 2. Detection and quantitation were linear over the range of DNA concentrations examined. To determine the number of $E$. coli cells, the fluorescent signals detected from two serial dilutions in the linear range of the assay were averaged and compared to a standard curve (Figure 2).

\section{Genotyping of $E$. coli using pulsed-field gel electrophoresis (PFGE)}

To genotype and compare E. coli strains isolated from the inflammatory and unchanged tissues from the same patient, we performed comparative analysis using PFGE. Preparation of the agarose blocks, conditions of

Table 1 Primers and probes used in this study

\begin{tabular}{lll}
\hline Gene & $\begin{array}{l}\text { Product } \\
\text { size }[\mathbf{b p}]\end{array}$ & Oligonucleotide sequence \\
\hline hlyA & 1177 & GTA TAC ACA AAA GAA GGA AGC \\
& & ACA GAA TCG TCA GCA TCA GC \\
iron & 667 & AAG TCA AAG CAG GGG TTG CCC G \\
& & GACGCCGACATAAGACGCAG \\
iutA & 302 & GGC TGG ACA TCA TGG GAA CTG G \\
& & CGT CGG GAA CGG GTA GAA TCG \\
iha & 829 & CTG GCG GAG GCT CTG AGA TCA \\
& & TCC TA AGC TCC CGC GGC TGA \\
ireA & 254 & GAT GAC TCA GCC ACG GGT AA \\
& & CCA GGA CTCA CCT CAC GAA T \\
chuA & 279 & GAC GAA CCA ACG GTC AGG AT \\
& & TGC CGC CAG TAC CAA AGA CA
\end{tabular}

Primers and probe specific for E. coli strains (Real-time PCR)

16S rRNA 204 GGG AGT AAA GTT AAT ACC TाT GC CTC AAG CTT GCC AGT ATC AG

Probe HEX- CGC GAT CAC TCC GTG CCA GCA GCC GCG GAT CGC G -BHQ1 


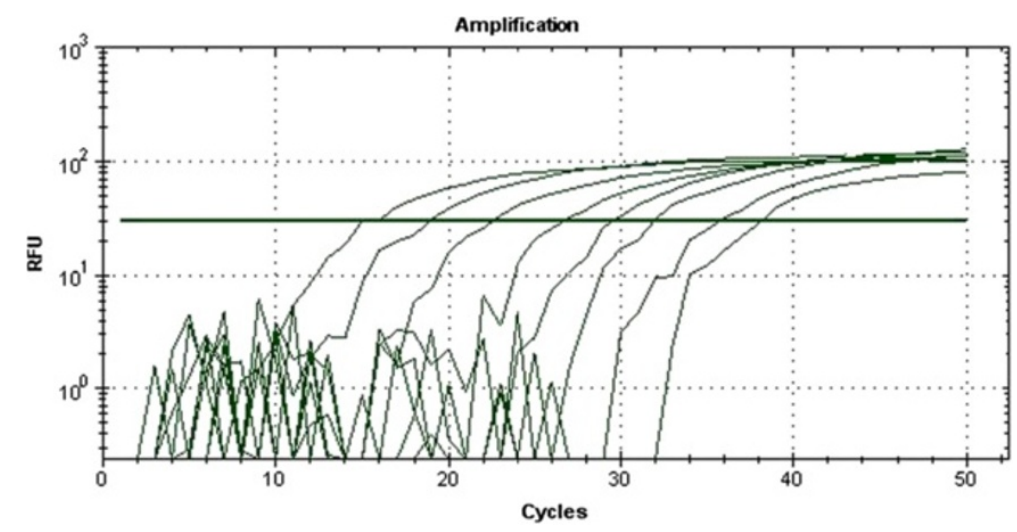

Figure 1 Relative fluorescence is the increase in reporter dye intensity relative to the passive internal reference dye. The amount of E. coli DNA in each sample is shown in the key. The threshold fluorescence, or level at which the threshold cycle was determined, is shown.

enzymatic digestion with $X b a \mathrm{I}$ and electrophoretic parameters were carried out according to the international PulseNet CDC (PulseNet 2002) guidelines [22]. The reference strain - Salmonella Braenderup H9812 - was obtained by courtesy of the staff of the National Institute of Public Health - National Institute of Hygiene in Warsaw. PFGE banding patterns were analyzed with the Molecular Analyst software (BioRad) using Dice coefficient and UPGMA (unweighted pair group method with arithmetic averages) algorithm.

\section{Multiplex PCR}

When choosing genes for PCR, we concentrated on the property of $E$. coli to acquire iron ions, that is: $\operatorname{iroN}$, iut $A$, ire $A$ and $c h u A$ genes coding receptor proteins for siderophores; iha coding the protein analog of adhesin; and $h l y A$ gene responsible for hemolysin $\alpha$ synthesis, the enzyme that degrades erythrocytes and liberates hemin. Multiplex PCR was performed according to the method of Zhao et al. [23] and PCR following the procedure of
Aranda et al. [24]. Primer sequences and the size of the amplification products are shown in Table 1.

\section{Detection of hemolytic activity}

All isolated E. coli strains were tested for the production of hemolysin on blood agar plates, prepared with defibrinated sheep blood washed three times and added to Trypticase Soy Agar (Columbia Lab Agar; Biocorp) at a final concentration of 5\%. Production of hemolysis was characterized by the formation of a clear halo around bacterial colonies after overnight incubation at $37^{\circ} \mathrm{C}$. The absence of hemolytic activity characterized nonhemolytic E. coli strains.

\section{Evaluation of relations between numbers of $E$. coli expressing iroN, iutA, iha, ireA, chuA and hlyA and their isolation sites}

To obtain a general model for the factors influencing the number of bacteria, a multivariate statistical model was constructed. The model was based on the general linear model assumption. Bacterial abundance was assumed to

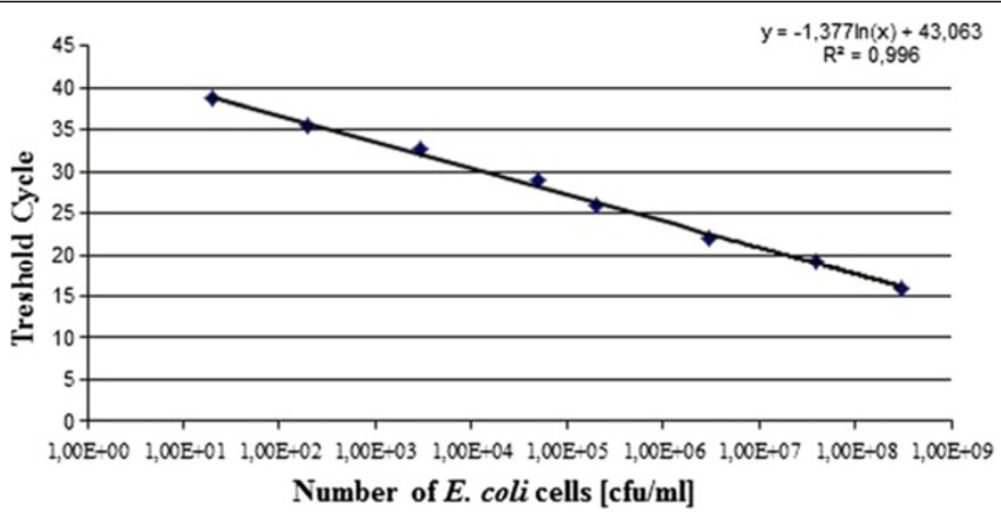

Figure 2 Standard curve was generated from the amplification plot in Figure 1. $y=-1.377 \ln (x)+43.063$; correlation coefficient $=0.996$. Threshold cycle was the cycle number when the threshold fluorescence was reached. 
be the continuous variable with exponential distribution dependent on the set of categorical predictors: absence of the analyzed genes (iroN, iutA, iha, ireA, chuA and $h l y A)$; group of patients; and the site of material origin.

\section{Statistical analysis}

Statistical analysis was done using Microsoft Access and Statistica software packages. Likelihood ratio and $X^{2}$ tests were used. $P<0.05$ was considered significant. The model used to evaluate the relations between the numbers of E. coli expressing the different genes and their isolation sites significantly explained the statistical relations $\left(\chi^{2}=65,2614, \mathrm{df}=8, P<0.0001\right)$.

\section{Results}

Qualitative and quantitative assessment of bacterial species based on culture methods

Based on classical culture methods, we showed that there were significantly more lactobacilli in the inflammatory tissues (Sample A) compared to the control group $(P=0.044)$, and in the noninflammatory mucosa (Sample B) compared to the control group $(P=0.041)$. There were no significant differences in the numbers of Enterococcus, Streptococcus and Bifidobacterium isolated from inflammatory and unchanged tissues in patients with UC compared with the control group. For Enterobacteriacae with special consideration of E. coli, no quantitative differences were observed between the $\mathrm{UC}$ patients and control group. The results are shown in Table 2.

Based on culture methods, 52 E. coli strains were isolated from 18 patients with acute-phase UC: 25 strains from Samples A, 27 strains from Samples B, and 18 strains from 12 patients in the control group. In total, 70 E. coli strains were investigated further.
Quantitative assessment of E. coli based on real-time PCR The bacterial DNA sequences isolated from all 76 tissue samples were analyzed. The presence of $E$. coli DNA was confirmed in 48 tissue samples (including 36 samples from 18 patients with acute-phase UC: Sample A, $n=18$; Sample $\mathrm{B}, \mathrm{n}=18$; and from 12 patients in the control group, Sample C, $\mathrm{n}=12$. There was a significant increase in the E. coli populations in the inflammatory tissues (Sample A) from patients with UC compared with the control group $(P=0.031)$, but not in the non-inflammatory tissues (Sample B). The results are shown in Table 3.

\section{PGFE genotyping of $E$. coli isolated from inflammatory} and unaffected tissues in patients with active-phase UC Isolated $E$. coli strains were characterized by high genetic variability. The analyses were done for all patients with confirmed $E$. coli strains $(\mathrm{n}=18)$, including 52 strains originating from Samples A (25 strains) and Samples B (27 strains). Among the 52 strains, 32 different pulsotypes were noted. In 15 patients (83\%), the E. coli strains isolated from inflammatory and unchanged tissues had identical restriction profiles. Only three patients had genetically different strains isolated from Sample A vs. Sample B. Additionally, in eight patients there was more than one E. coli strain isolated from the given site with a unique genetic profile. The results are shown in Figure 3.

\section{Frequency of genes responsible for synthesis of proteins} for acquisition of iron ions

Based on PCR, we tested for the frequency of genes in the genomes of $70 \mathrm{E}$. coli strains. Analyzing the frequency of the genes responsible for synthesis of proteins for acquisition of iron ions (iroN, iutA, iha, ireA, chuA and $h l y A$ ), we showed significant differences in relation to the frequency of iro $N$ gene coding the protein responsible for binding siderophores. The iroN gene was

Table 2 Numbers of bacteria isolated from inflammatory and unchanged colonic mucosa in patients with UC

\begin{tabular}{|c|c|c|c|}
\hline \multirow[t]{2}{*}{ Bacteria } & \multicolumn{2}{|c|}{ Average bacterial no. [c.f.u/g] isolated from patients in active phase of $U C, n=30$} & \multirow{2}{*}{$\begin{array}{l}\text { Control group, } \\
\text { (sample C, } n=16 \text { ) }\end{array}$} \\
\hline & $\begin{array}{l}\text { Inflammatorily changed site biopsy } \\
(\text { sample } A, n=30)\end{array}$ & $\begin{array}{l}\text { Unchanged mucosal biopsy } \\
\text { (sample } B, n=30)\end{array}$ & \\
\hline Sume of cultured bacteria & $3.1 \cdot 10^{7} \pm 1.6 \cdot 10^{7}$ & $6.4 \cdot 10^{7} \pm 4.8 \cdot 10^{7}$ & $7.6 \cdot 10^{7} \pm 6.1 \cdot 10^{7}$ \\
\hline Enterobacteriaceaae & $5.0 \cdot 10^{6} \pm 1.8 \cdot 10^{6}$ & $2.1 \cdot 10^{7} \pm 1.1 \cdot 10^{7}$ & $1.5 \cdot 10^{7} \pm 8.1 \cdot 10^{6}$ \\
\hline Escherichia coli ${ }^{* * *}$ & $3.3 \cdot 10^{6} \pm 3.1 \cdot 10^{6}$ & $1.3 \cdot 10^{6} \pm 1.1 \cdot 10^{6}$ & $1.6 \cdot 10^{6} \pm 1.2 \cdot 10^{6}$ \\
\hline Enterococcus & $8.9 \cdot 10^{6} \pm 6.3 \cdot 10^{6}$ & $9.5 \cdot 10^{6} \pm 4.5 \cdot 10^{6}$ & $4.5 \cdot 10^{6} \pm 3.4 \cdot 10^{6}$ \\
\hline Streptococcus & $3.2 \cdot 10^{6} \pm 2.0 \cdot 10^{6}$ & $9.1 \cdot 10^{6} \pm 6.8 \cdot 10^{6}$ & $7.1 \cdot 10^{6} \pm 5.9 \cdot 10^{6}$ \\
\hline Lactobacillus & $5.2 \cdot 10^{6} \pm 3.0 \cdot 10^{6 *}$ & $8.5 \cdot 10^{6} \pm 5.0 \cdot 10^{6} * *$ & $7.6 \cdot 10^{5} \pm 4.4 \cdot 10^{5}$ \\
\hline Bifidobacterium & $5.1 \cdot 10^{6} \pm 3.5 \cdot 10^{6}$ & $2.1 \cdot 10^{6} \pm 1.1 \cdot 10^{6}$ & $2.7 \cdot 10^{5} \pm 1.2 \cdot 10^{5}$ \\
\hline
\end{tabular}

Results based on culture methods.

${ }^{*}$ Numbers significantly different from the control group $\left({ }^{*} P=0.044 ; * * P=0.041\right)$.

*** E. coli was found in only 18 patients with active-phase UC and 12 patients from the control group. 
Table 3 Numbers of bacteria isolated from inflammatory and unchanged colonic mucosa in patients with UC

\begin{tabular}{|c|c|c|c|}
\hline \multirow[t]{2}{*}{ Bacteria } & \multicolumn{2}{|c|}{ Average bacterial no. [c.f.u/g] isolated from patients in active phase of UC, $n=30$} & \multirow{2}{*}{$\begin{array}{c}\text { Control group, } \\
\text { (sample } C, n=16 \text { ) }\end{array}$} \\
\hline & $\begin{array}{l}\text { Inflammatorily changed site biopsy } \\
\text { (sample } A, n=30 \text { ) }\end{array}$ & $\begin{array}{l}\text { Unchanged mucosal biopsy } \\
\text { (sample } B, n=30)\end{array}$ & \\
\hline Escherichia coli $* * *$ & $3.95 \cdot 10^{13} \pm 3.9 \cdot 10^{13 *}$ & $2.21 \cdot 10^{10} \pm 3.1 \cdot 10^{10}$ & $9.17 \cdot 10^{10} \pm 6.5 \cdot 10^{10}$ \\
\hline
\end{tabular}

confirmed in 17 of 25 E. coli strains isolated from Samples A (inflammatory tissue); in 18 of 27 strains isolated from Samples B (unchanged tissue); as well as in six of 18 strains isolated from patients in the control group. A higher number of $E$. coli isolates from UC patients had the iroN gene in comparison with the strains isolated from the control group. No significant differences were shown for the frequency of the iroN gene in the strains from Samples A and B from the same patient. The results are shown in Table 4 and Figure 4.

\section{Detection of hemolytic activity}

When analyzing the ability of $E$. coli to lyse red blood cells, 10 of 70 strains cultured on blood agar showed phenotypic hemolytic characteristics. $\alpha$-Hemolysis in selected strains is shown in Figure 5. Furthermore, $70 \mathrm{E}$. coli strains were tested with PCR to confirm the presence of the $h l y A$ gene, which is responsible for biosynthesis of $\alpha$-hemolysin. In 10 strains that showed phenotypic $\alpha$ hemolysis, the presence of $h l y A$ was confirmed. These strains were isolated with the same frequency from inflammatory and unchanged tissues.

\section{Relations between numbers of $E$. coli expressing iroN, iut $A$, iha, ire $A$, chu $A$ and $h l y A$ and their isolation sites} Analysis showed that three predictors significantly influenced the dependent variable: presence of genes $\operatorname{chuA}$ and $i u t A$ as well as place of origin (inflammatory colonic mucosa, Sample A and unchanged mucosa, Sample B). Presence of chuA and iutA genes in E. coli correlated with the increase in bacteria assessed using real-time PCR in the inflammatory tissues where there was more free iron available.

\section{Discussion}

Currently, a lot of attention is given to the role of commensal bacteria in the human GI tract, the numbers of which change in relation to persistent intestinal inflammatory processes $[2,7-9,25]$.

Mylonaki et al. have shown a significant increase in the population of $E$. coli from colonic mucosa biopsies collected from UC patients compared with those in remission and the control group [26]. Kleessen at al. [27] have analyzed quantitative changes in bacterial populations in patients with UC versus a control group, and demonstrated an increase in the populations of Enterobacteriacae, including E. coli. In both studies, the quantitative analysis was based on fluorescence in situ hybridization (FISH).

We confirmed the relationship between an increase in the population of Gram-negative rods (E. coli) and exacerbation of clinical symptoms of UC. Based on real-time PCR, we demonstrated a significant increase in E. coli in inflammatory tissues in patients with UC compared with the control group.

In most recent studies, microorganisms in tissue samples from patients with different IBDs have been assessed using molecular methods (e.g. PCR, real-time PCR, and FISH), which allow one to detect even trace amounts of microbial DNA. These methods are especially useful for quantitative analysis of tissue samples from patients with chronic inflammatory diseases. In places where there are ongoing biochemical reactions related to the inflammatory process, reactive oxygen species (ROS) are abundant, which has a direct influence causing a decrease in viability of bacterial cells [28]. These reactions are very dynamic, leading to sudden changes in bacterial populations, depending on the presence of multiple proinflammatory factors. Using methods with the highest sensitivity (real time PCR) play a key role in such a situation. The real-time PCR system of Ott et al. [29] provides an accurate and stable method to measure bacterial concentrations in clinical samples, but validation of the results obtained by real-time PCR with traditional bacterial culture methods is difficult to perform and can generate mean differences [29]. Therefore qualitative and quantitative assessment based solely on classical culture methods during exacerbation of the inflammatory process in the GI tract seems insufficient. This may also explain the differences observed in our studies.

The results presented above from our as well as other studies point to a relation between the quantitative changes in E. coli and the course of UC. Wohlgemuth et al. used mouse models $(129 / \mathrm{SvEv})$ to try to explain quantitative and qualitative changes within the commensal microbiota during inflammation of the GI tract. Their study showed a decrease in variability of microorganisms and a strong increase in E. coli numbers during the development of inflammation. At the same time, they found that there was a lack of evidence directly 


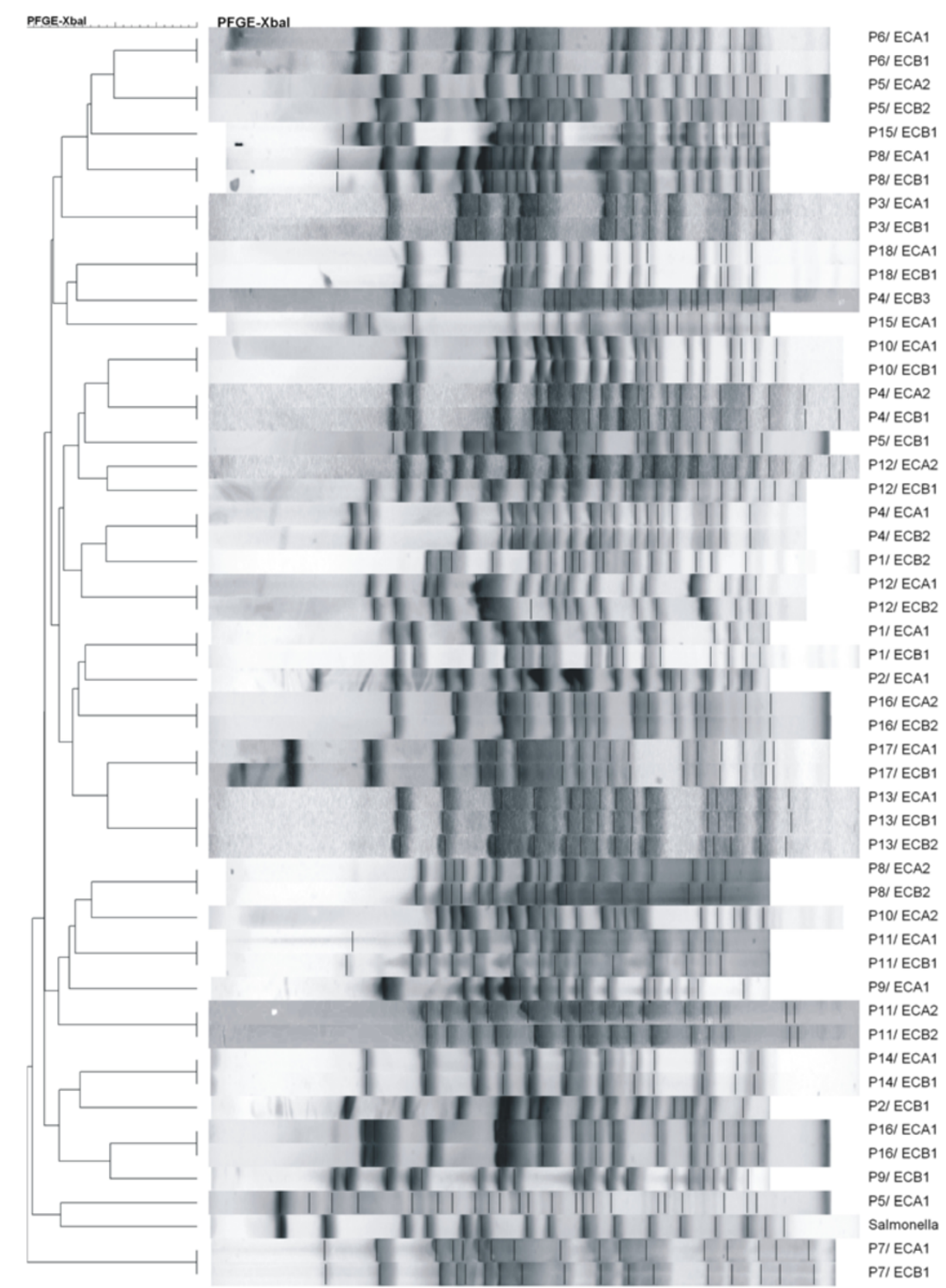

Figure 3 Comparison of restriction patterns of $E$. coli isolated from patients with active-phase UC. Results based on PFGE. P1/ECA1P18/ECB1 - strains isolated from UC patients (A-inflammatorily changed place, B - unchanged mucosa, reference strain - Salmonella Braenderup H9812.

pointing to the increased numbers of E. coli as the reason for exacerbation of the inflammatory process. In fact, their conclusion was that the conditions that accompany acute inflammation, favor E. coli proliferation [10].

The increase in E. coli populations probably depends on many adaptive factors, for example, biofilm formation, synthesis of enzymes able to catalyze breakdown of ROS, use of supportive mechanisms allowing absorption of iron ions from the environment, and ability to acquire iron ions by using hemoglobin from lysed erythrocytes $[10,12]$.

For bacteria colonizing the human GI tract, especially Enterobacteriacae, to obtain enough iron for their cells is difficult, owing to the fact that iron is contained in complexes with host proteins (e.g. hemoglobin, transferrin, and lactoferrin) [30]. E. coli has the ability to lyse red blood cells, degrade hemoglobin, and acquire iron as 
Table 4 Frequency of genes responsible for synthesis of proteins for acquisition of iron ions

\begin{tabular}{|c|c|c|c|c|c|c|c|}
\hline \multirow[t]{2}{*}{ Number } & \multirow{2}{*}{$\begin{array}{l}\text { Hemolysis - } \\
\text { phenotypic }\end{array}$} & \multicolumn{6}{|c|}{ Gene presence } \\
\hline & & hlyA & iha & iroN & chuA & iutA & ireA \\
\hline P1/ECA1 & {$[-]$} & {$[-]$} & {$[-]$} & {$[-]$} & {$[-]$} & {$[-]$} & {$[-]$} \\
\hline $\mathrm{P} 1 / \mathrm{ECB} 1$ & {$[-]$} & {$[-]$} & {$[-]$} & {$[-]$} & {$[-]$} & {$[-]$} & {$[-]$} \\
\hline P1/ECB2 & {$[+]$} & {$[+]$} & {$[-]$} & {$[+]$} & {$[+]$} & {$[-]$} & {$[-]$} \\
\hline $\mathrm{P} 2 / \mathrm{ECA} 1$ & {$[-]$} & {$[-]$} & {$[-]$} & {$[+]$} & {$[-]$} & {$[+]$} & {$[+]$} \\
\hline $\mathrm{P} 2 / \mathrm{ECB} 1$ & {$[-]$} & {$[-]$} & {$[-]$} & {$[-]$} & {$[-]$} & {$[-]$} & {$[-]$} \\
\hline P3/ECA1 & {$[-]$} & {$[-]$} & {$[-]$} & {$[+]$} & {$[+]$} & {$[-]$} & {$[-]$} \\
\hline P3/ECB1 & {$[-]$} & {$[-]$} & {$[-]$} & {$[+]$} & {$[+]$} & {$[+]$} & {$[-]$} \\
\hline $\mathrm{P} 4 / \mathrm{ECA} 1$ & {$[-]$} & {$[-]$} & {$[-]$} & {$[+]$} & {$[-]$} & {$[-]$} & {$[-]$} \\
\hline P4/ECA2 & {$[-]$} & {$[-]$} & {$[-]$} & {$[+]$} & {$[-]$} & {$[-]$} & {$[-]$} \\
\hline P4/ECB1 & {$[-]$} & {$[-]$} & {$[-]$} & {$[+]$} & {$[-]$} & {$[-]$} & {$[-]$} \\
\hline P4/ECB2 & {$[-]$} & {$[-]$} & {$[-]$} & {$[+]$} & {$[-]$} & {$[-]$} & {$[-]$} \\
\hline P4/ECB3 & {$[-]$} & {$[-]$} & {$[-]$} & {$[+]$} & {$[-]$} & {$[+]$} & {$[-]$} \\
\hline P5/ECA1 & {$[-]$} & {$[-]$} & {$[-]$} & {$[+]$} & {$[+]$} & {$[-]$} & {$[-]$} \\
\hline P5/ECA2 & {$[-]$} & {$[-]$} & {$[-]$} & {$[-]$} & {$[-]$} & {$[-]$} & {$[-]$} \\
\hline P5/ECB1 & {$[-]$} & {$[-]$} & {$[-]$} & {$[+]$} & {$[+]$} & {$[-]$} & {$[-]$} \\
\hline P5/ECB2 & {$[-]$} & {$[-]$} & {$[-]$} & {$[-]$} & {$[-]$} & {$[+]$} & {$[-]$} \\
\hline P6/ECA1 & {$[-]$} & {$[-]$} & {$[-]$} & {$[-]$} & {$[-]$} & {$[-]$} & {$[-]$} \\
\hline P6/ECB1 & {$[-]$} & {$[-]$} & {$[-]$} & {$[-]$} & {$[-]$} & {$[-]$} & {$[-]$} \\
\hline P7/ECA1 & {$[-]$} & {$[-]$} & {$[-]$} & {$[+]$} & {$[-]$} & {$[+]$} & {$[-]$} \\
\hline P7/ECB1 & {$[-]$} & {$[-]$} & {$[-]$} & {$[+]$} & {$[-]$} & {$[+]$} & {$[-]$} \\
\hline P8/ECA1 & {$[+]$} & {$[+]$} & {$[-]$} & {$[+]$} & {$[+]$} & {$[-]$} & {$[-]$} \\
\hline P8/ECA2 & {$[-]$} & {$[-]$} & {$[+]$} & {$[-]$} & {$[+]$} & {$[+]$} & {$[-]$} \\
\hline P8/ECB1 & {$[+]$} & {$[+]$} & {$[-]$} & {$[+]$} & {$[+]$} & {$[-]$} & {$[-]$} \\
\hline P8/ECB2 & {$[-]$} & {$[-]$} & {$[+]$} & {$[-]$} & {$[+]$} & {$[+]$} & {$[-]$} \\
\hline P9/ECA1 & {$[-]$} & {$[-]$} & {$[-]$} & {$[+]$} & {$[-]$} & {$[+]$} & {$[-]$} \\
\hline P9/ECB1 & {$[-]$} & {$[-]$} & {$[+]$} & {$[-]$} & {$[+]$} & {$[+]$} & {$[-]$} \\
\hline $\mathrm{P} 10 / \mathrm{ECA} 1$ & {$[-]$} & {$[-]$} & {$[-]$} & {$[+]$} & {$[-]$} & {$[-]$} & {$[-]$} \\
\hline $\mathrm{P} 10 / \mathrm{ECA} 2$ & {$[-]$} & {$[-]$} & {$[-]$} & {$[+]$} & {$[-]$} & {$[+]$} & {$[+]$} \\
\hline $\mathrm{P} 10 / \mathrm{ECB} 1$ & {$[-]$} & {$[-]$} & {$[-]$} & {$[+]$} & {$[-]$} & {$[+]$} & {$[+]$} \\
\hline $\mathrm{P} 11 / \mathrm{ECA} 1$ & {$[-]$} & {$[-]$} & {$[-]$} & {$[+]$} & {$[-]$} & {$[+]$} & {$[-]$} \\
\hline $\mathrm{P} 11 / \mathrm{ECA} 2$ & {$[-]$} & {$[-]$} & {$[-]$} & {$[+]$} & {$[+]$} & {$[+]$} & {$[-]$} \\
\hline P11/ECB1 & {$[-]$} & {$[-]$} & {$[-]$} & {$[+]$} & {$[-]$} & {$[+]$} & {$[-]$} \\
\hline $\mathrm{P} 11 / \mathrm{ECB} 2$ & {$[-]$} & {$[-]$} & {$[-]$} & {$[+]$} & {$[+]$} & {$[+]$} & {$[-]$} \\
\hline $\mathrm{P} 12 / \mathrm{ECA} 1$ & {$[-]$} & {$[-]$} & {$[-]$} & {$[+]$} & {$[+]$} & {$[+]$} & {$[-]$} \\
\hline $\mathrm{P} 12 / \mathrm{ECA} 2$ & {$[+]$} & {$[+]$} & {$[-]$} & {$[-]$} & {$[-]$} & {$[-]$} & {$[-]$} \\
\hline $\mathrm{P} 12 / \mathrm{ECB} 1$ & {$[+]$} & {$[+]$} & {$[-]$} & {$[+]$} & {$[+]$} & {$[+]$} & {$[-]$} \\
\hline $\mathrm{P} 12 / \mathrm{ECB} 2$ & {$[-]$} & {$[-]$} & {$[-]$} & {$[+]$} & {$[+]$} & {$[-]$} & {$[-]$} \\
\hline $\mathrm{P} 13 / \mathrm{ECA} 1$ & {$[+]$} & {$[+]$} & {$[+]$} & {$[-]$} & {$[+]$} & {$[+]$} & {$[-]$} \\
\hline $\mathrm{P} 13 / \mathrm{ECB} 1$ & {$[+]$} & {$[+]$} & {$[+]$} & {$[-]$} & {$[+]$} & {$[+]$} & {$[-]$} \\
\hline $\mathrm{P} 13 / \mathrm{ECB} 2$ & {$[+]$} & {$[+]$} & {$[+]$} & {$[-]$} & {$[+]$} & {$[+]$} & {$[-]$} \\
\hline $\mathrm{P} 14 / \mathrm{ECA} 1$ & {$[-]$} & {$[-]$} & {$[-]$} & {$[+]$} & {$[-]$} & {$[-]$} & {$[-]$} \\
\hline $\mathrm{P} 14 / \mathrm{ECB} 1$ & {$[-]$} & {$[-]$} & {$[-]$} & {$[+]$} & {$[-]$} & {$[-]$} & {$[-]$} \\
\hline
\end{tabular}

Table 4 Frequency of genes responsible for synthesis of proteins for acquisition of iron ions (Continued)

\begin{tabular}{llllllll}
\hline P15/ECA1 & {$[-]$} & {$[-]$} & {$[-]$} & {$[-]$} & {$[-]$} & {$[-]$} & {$[-]$} \\
P15/ECB1 & {$[-]$} & {$[-]$} & {$[-]$} & {$[-]$} & {$[-]$} & {$[-]$} & {$[-]$} \\
P16/ECA1 & {$[-]$} & {$[-]$} & {$[-]$} & {$[-]$} & {$[-]$} & {$[-]$} & {$[-]$} \\
P16/ECA2 & {$[-]$} & {$[-]$} & {$[-]$} & {$[+]$} & {$[-]$} & {$[+]$} & {$[-]$} \\
P16/ECB1 & {$[-]$} & {$[-]$} & {$[-]$} & {$[+]$} & {$[-]$} & {$[+]$} & {$[-]$} \\
P16/ECB2 & {$[-]$} & {$[-]$} & {$[-]$} & {$[+]$} & {$[-]$} & {$[+]$} & {$[-]$} \\
P17/ECA1 & {$[-]$} & {$[-]$} & {$[-]$} & {$[+]$} & {$[+]$} & {$[+]$} & {$[-]$} \\
P17/ECB1 & {$[-]$} & {$[-]$} & {$[-]$} & {$[+]$} & {$[+]$} & {$[+]$} & {$[-]$} \\
P18/ECA1 & {$[-]$} & {$[-]$} & {$[-]$} & {$[+]$} & {$[-]$} & {$[-]$} & {$[-]$} \\
P18/ECB1 & {$[-]$} & {$[-]$} & {$[-]$} & {$[+]$} & {$[-]$} & {$[-]$} & {$[-]$} \\
P1/ECC1 & {$[-]$} & {$[-]$} & {$[-]$} & {$[+]$} & {$[-]$} & {$[+]$} & {$[-]$} \\
P1/ECC2 & {$[+]$} & {$[+]$} & {$[+]$} & {$[+]$} & {$[+]$} & {$[+]$} & {$[-]$} \\
P2/ECC1 & {$[-]$} & {$[-]$} & {$[+]$} & {$[-]$} & {$[+]$} & {$[+]$} & {$[-]$} \\
P3/ECC1 & {$[-]$} & {$[-]$} & {$[-]$} & {$[+]$} & {$[+]$} & {$[+]$} & {$[-]$} \\
P3/ECC2 & {$[-]$} & {$[-]$} & {$[-]$} & {$[+]$} & {$[+]$} & {$[-]$} & {$[-]$} \\
P4/ECC1 & {$[-]$} & {$[-]$} & {$[-]$} & {$[-]$} & {$[+]$} & {$[-]$} & {$[-]$} \\
P5/ECC1 & {$[-]$} & {$[-]$} & {$[-]$} & {$[-]$} & {$[+]$} & {$[-]$} & {$[-]$} \\
P5/ECC2 & {$[-]$} & {$[-]$} & {$[-]$} & {$[-]$} & {$[-]$} & {$[-]$} & {$[-]$} \\
P6/ECC1 & {$[-]$} & {$[-]$} & {$[-]$} & {$[-]$} & {$[-]$} & {$[+]$} & {$[-]$} \\
P7/ECC1 & {$[-]$} & {$[-]$} & {$[+]$} & {$[-]$} & {$[+]$} & {$[-]$} & {$[-]$} \\
P8/ECC1 & {$[+]$} & {$[+]$} & {$[-]$} & {$[-]$} & {$[+]$} & {$[+]$} & {$[-]$} \\
P8/ECC2 & {$[-]$} & {$[-]$} & {$[+]$} & {$[-]$} & {$[+]$} & {$[-]$} & {$[-]$} \\
P9/ECC1 & {$[-]$} & {$[-]$} & {$[-]$} & {$[+]$} & {$[-]$} & {$[-]$} & {$[-]$} \\
P10/ECC1 & {$[-]$} & {$[-]$} & {$[-]$} & {$[-]$} & {$[-]$} & {$[+]$} & {$[-]$} \\
P10/ECC2 & {$[-]$} & {$[-]$} & {$[+]$} & {$[-]$} & {$[+]$} & {$[+]$} & {$[-]$} \\
P11/ECC1 & {$[-]$} & {$[-]$} & {$[-]$} & {$[+]$} & {$[+]$} & {$[+]$} & {$[-]$} \\
P12/ECC1 & {$[-]$} & {$[-]$} & {$[-]$} & {$[-]$} & {$[-]$} & {$[-]$} & {$[-]$} \\
P12/ECC2 & {$[-]$} & {$[-]$} & {$[-]$} & {$[-]$} & {$[+]$} & {$[-]$} & {$[-]$} \\
\hline CE5 S4d1 & {$[-]$} & {$[-]$}
\end{tabular}

Genes studied: iroN, iutA, iha, ireA, chuA and hlyA.

+ positive result; - : negative result.

P1/ECA1-P18/ECB1: strains isolated from UC patients (A: inflammatory tissues; $B$ : unchanged mucosa); P1/ECC1-P12/ECC2: strains isolated from the control group.

a result of the ChuA receptor on the outer membrane [12]. In our study, we noted a significant increase in E. coli that possessed the chuA gene, which codes for a receptor for hemin from lysed erythrocytes. This was confirmed in patients with UC in an inflammatory tissue. Similarly, a significant relation was confirmed for E. coli bearing the iutA gene, which is responsible for coding a receptor that allows absorption of iron chelated by one of the siderophores (aerobactin) [30]. The presence of the chuA and iutA genes in $E$. coli correlates with the increased numbers of bacteria assessed using real-time PCR in inflammatory tissues where more free iron is available. Additionally, we observed significant differences in the presence of $i r o N$ gene in $E$. coli. The iroN gene encodes a receptor that is responsible for 


\section{Distribution percentage of E.coli with confirmed presence of iroN gene according to place of collection}

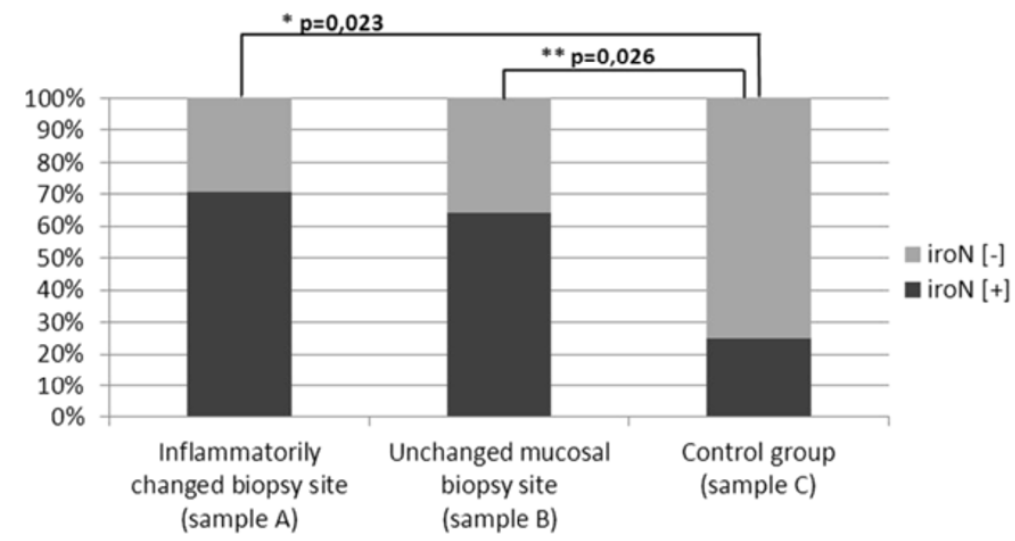

Figure 4 Distribution of $E$. coli with confirmed iroN gene. Specimens isolated from colon mucosa with inflammatory changes and unchanged mucosa from patients with active-phase UC compared with the control group.

identifying and binding siderophores (glucosylated enterobactins), expression of which depends on the presence of iron ions in the environment [30]. The presence of iroN gene was confirmed in $70 \%$ and $65 \%$ of E. coli strains isolated from inflammatory and unchanged tissues in UC patients, respectively, compared with $25 \%$ of strains from the control group. Based on our present and other previous studies [10], we can conclude that increased availability of iron ions in the GI tract of patients with $\mathrm{UC}$ is a significant factor related to the quantitative increase in E. coli.

Our study not only assessed E. coli quantitatively in UC and control group patients, but also compared the genetic profiles of the strains based on PFGE. Comparative analysis of the restriction patterns confirmed high variability among the $E$. coli strains. It seems that the focal inflammatory state does not favor adhesion of a specific type of E. coli. In $83 \%$ of cases (15/18 patients), genetically identical $E$. coli were isolated from inflammatory lesions compared with unchanged tissue. Different profiles of E. coli collected from the two types of tissues were demonstrated in only three patients. There were no similarities between strains isolated from different patients. Similar confirmatory results were obtained by Thomazini et al. [31], who used ERIC2-PCR (Enterobacterial Repetitive Intergenic Consensus-PCR) in their analysis of $131 \mathrm{E}$. coli strains isolated from patients with IBD (including UC) and a control group. They demonstrated unequivocally that there was no specific strain or group of strains of E. coli related to UC or Crohn's disease, or in the control group. Sepehri et al. [2] have compared E. coli strains from patients with IBD (including UC) and a control group, using MLST (Multilocus Sequence Typing). Three main groups of $E$. coli were drawn but no relation was found for the strains and disease entity.

It is worth mentioning that so far there is no proof of a single E. coli strain participating in the etiopathogenesis of UC [16]. It is more often considered that there is an increase in $E$. coli populations that can bind free iron ions by siderophores [12] and store iron intracellularly [32], which allows them to inhibit the Fenton reaction in the intestine, by eliminating iron ions and prevention of ROS formation, and at the same time reducing damage to the host tissues [28]. Furthermore, considering the role of $E$. coli as an anti-inflammatory
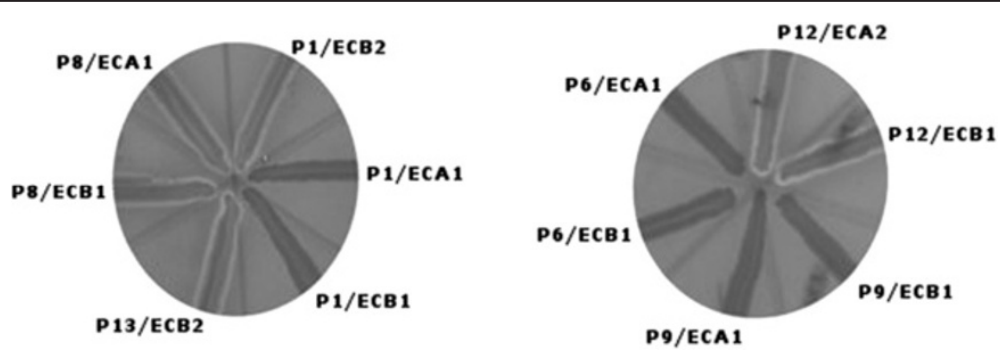

Figure 5 a-Hemolysis visible on blood agar. E. coli: P1/ECB2, P8/ECA1, P8/ECB1, P12/ECA2, P12/ECB1, P13/ECB2 - visible type alpha hemolysis, strains: P1/ECA1, P1/ECB1, P6/ECA1, P6/ECB1, P9/ECA1, P9/ECB1 - no alpha hemolysis. 
and facilitating remission, there have been some studies on E. coli Nissle as a probiotic [33].

\section{Abbreviations}

Gl: Gastrointestinal tract; IBD: Inflammatory bowel diseases; PCR: Polymerase chain reaction; PFGE: Pulsed field gel electrophoresis; ROS: Reactive oxygen species UC ulcerative colitis.

\section{Competing interests}

The authors declare that they have no competing interests.

\section{Authors' contributions}

MPZ, AC, TG and AT carried out the diagnosis of bacterial strains and molecular genetic studies; PA participated in statistical analysis of the data; MZW and TM carried out the clinical research; MS and PBH contributed to conception and design of the project and were involved in data analysis and interpretation of results. All authors read and approved the final manuscript.

\section{Acknowledgments}

This study was supported by grants no. N N402 086134 and N N401 144638 from the Polish Ministry of Research and Higher Education.

\section{Author details}

'Department of Microbiology, Jagiellonian University Medical College, Czysta 18 Street, Cracow 31-121, Poland. ${ }^{2}$ Polish Academy of Sciences, Institute of Nature Conservation, 33 Mickiewicza Avenue, Cracow 31-120, Poland. ${ }^{3}$ Department of Gastroenterology, Hepatology and Infectious Diseases, Jagiellonian University Medical College, Śniadeckich 5 Street, Cracow 31-531, Poland.

Received: 17 October 2012 Accepted: 19 March 2013

Published: 8 April 2013

\section{References}

1. Mpofu C: Ireland. Inflammatory bowel disease-the disease and it's diagnosis. Hospital Pharmacist 2006, 13:153-158.

2. Sepehri S, Kotlowski R, Bernstein CN, Krause DO: Microbial diversity of inflamed and noninflamed gut biopsy tissues in inflammatory bowel disease. Inflamm Bowel Dis 2007, 13(6):675-683.

3. Dudhgaonkar SP, Tandan SK, Kumar D, Raviprakash V, Kataria M: Influence of simultaneous inhibition of cyclooxygenase-2 and inducible nitric oxide synthase in experimental colitis in rats. Inflammopharmacology 2007, 15(5):188-195.

4. Sandborn WJ, Stenson WF, Brynskov J, Lorenz RG, Steidle GM, Robbins JL, Kent JD, Bloom BJ: Safety of celecoxib in patients with ulcerative colitis in remission: a randomized, placebo-controlled, pilot study. Clin Gastroenterol Hepatol 2006, 4(2):203-211.

5. Hulten K, El-Zimaity HM, Karttunen TJ, Almashhrawi A, Schwartz MR, Graham DY, El-Zaatari FA: Detection of Mycobacterium avium subspecies paratuberculosis in Crohn's diseased tissues by in situ hybridization. Am 」 Gastroenterol 2001, 96(5):1529-1535.

6. Strus M, Uhlig H, Powrie F, Hultgren Hornquist E, Bland P, Drzewiecki A, Kochan P, Heczko PB: A role of bacteria in inflammatory bowel disease evoked in animal models. Gastroenterol Pol 2005, 12:15-20

7. Gosiewski T, Strus M, Fyderek K, Kowalska-Duplaga K, Wedrychowicz A, Jedynak-Wasowicz U, Sladek M, Pieczarkowski S, Adamski P, Heczko P. Horizontal Distribution of the Fecal Microbiota in Adolescents With Inflammatory Bowel Disease. J Pediatr Gastroenterol Nutr 2012, 54(1):20-27.

8. Baumgart M, Dogan B, Rishniw M, Weitzman G, Bosworth B, Yantiss R, Orsi RH, Wiedmann M, McDonough P, Kim SG, Berg D, Schukken Y, Scherl E, Simpson KW: Culture independent analysis of ileal mucosa reveals a selective increase in invasive Escherichia coli of novel phylogeny relative to depletion of Clostridiales in Crohn's disease involving the ileum. ISME J 2007, 1(5):403-418. Epub 2007 Jul 12.

9. Kotlowski R, Bernstein CN, Sepehri S, Krause DO: High prevalence of Escherichia coli belonging to the B2+D phylogenetic group in inflammatory bowel disease. Gut 2007, 56(5):669-675.

10. Wohlgemuth S, Haller D, Blaut M, Loh G: Reduced microbial diversity and high numbers of one single Escherichia coli strain in the intestine of colitic mice. Environ Microbiol 2009, 11(6):1562-1571.
11. Law D, Wilkie KM, Freeman R, Gould FK: The iron uptake mechanisms of enteropathogenic Escherichia coli: the use of haem and haemoglobin during growth in an iron-limited environment. J Med Microbiol 1992, 37(1):15-21.

12. Byron $\mathrm{CH}$, Chu $\mathrm{BC}$, Vogel $\mathrm{HJ}$ : A structural and functional analysis of type III periplasmic and substrate binding proteins: their role in bacterial siderophore and heme transport. Biol Chem 2011, 392(1-2):39-52.

13. Gentschev I, Dietrich G, Goebel W: The E. coli alpha-hemolysin secretion system and its use in vaccine development. Trends Microbiol 2002, 10(1):39-45.

14. Masseret E, Boudeau J, Colombel JF, Neut C, Desreumaux P, Joly B, Cortot A, Darfeuille-Michaud A: Genetically related Escherichia coli strains associated with Crohn's disease. Gut 2001, 48(3):320-325.

15. Darfeuille-Michaud A, Boudeau J, Bulois P, Neut C, Glasser AL, Barnich N, Bringer MA, Swidsinski A, Beaugerie L, Colombel JF: High prevalence of adherent-invasive Escherichia coli associated with ileal mucosa in Crohn's disease. Gastroenterology 2004, 127(2):412-421.

16. Simmonds NJ, Rampton DS: Inflammatory bowel disease a radical view. Gut 1993, 34:865-868.

17. Geboes K, Riddell R, Ost A, Jensfelt B, Persson T, Löfberg R: A reproducible grading scale for histological assessment of inflammation in ulcerative colitis. Gut 2000, 47(3):404-409.

18. Conte MP, Schippa S, Zamboni I, Penta M, Chiarini F, Seganti L, Osborn J, Falconieri P, Borrelli O, Cuchiara S: Gut-associated bacterial microbiota in paediatric patients with inflammatory bowel disease. Gut 2006, 55:1760-1767

19. Clark PA, Cotton LN, Martin JH: Selection of bifidobacteria for use as dietary adjuncts in cultured dairy foods. II. Tolerance to simulated $\mathrm{pH}$ of human stomachs. Cult Dairy Prod J. 1993, 28:11-14.

20. Chiba N, Murayama SY, Morozumi M, Nakayama E, Okada T, Iwata S, Sunakawa K, Ubukata K: Rapid detection of eight causative pathogens for the diagnosis of bacterial meningitis by real-time PCR. I Infect Chemother 2009, 15(2):92-98. Epub 2009 Apr 25.

21. Lyons SR, Griffen AL, Leys EJ: Quantitative real-time PCR for Porphyromonas gingivalis and total bacteria. J Clin Microbiol 2000, 38(6):2362-2365.

22. Online protocol 11. Pulse Net USA, Standardized Laboratory Protocol for Molecular Subtyping of Escherichia coli O157:H7, non-typhoidal Salmonella serotypes, and Shigella sonnei. Pulsed Field Gel Electrophoresis (PFGE); 2002.

23. Zhao L, Gao S, Huan H, Xu X, Zhu X, Yang W, Gao Q, Liu X: Comparison of virulence factors and expression of specific genes between uropathogenic Escherichia coli and avian pathogenic E. coli in a murine urinarytract infection model and a chicken challenge model. Microbiology 2009, 155:1634-1644.

24. Aranda KR, Fabbricotti SH, Fagundes-Neto U, Scaletsky IC: Single multiplex assay to identify simultaneously enteropathogenic, enteroaggregative, enterotoxigenic, enteroinvasive and Shiga toxinproducing Escherichia coli strains in Brazilian children. FEMS Microbiol Lett 2007, 267(2):145-150.

25. Strus M, Gosiewski T, Fyderek K, Wedrychowicz A, Kowalska-Duplaga K, Kochan P, Adamski P, Heczko PB: A role of hydrogen peroxide producing commensal bacteria present in colon of adolescents with inflammatory bowel disease in perpetuation of the inflammatory process. J Physiol Pharmacol 2009, 60(Suppl 6):49-54.

26. Mylonaki M, Rayment NB, Rampton DS, Hudspith BN, Brostoff J: Molecular characterization of rectal mucosa-associated bacterial flora in inflammatory bowel disease. Inflamm Bowel Dis 2005, 11(5):481-487.

27. Kleessen B, Kroesen AJ, Buhr HJ, Blaut M: Mucosal and invading bacteria in patients with inflammatory bowel disease compared with controls. Scand J Gastroenterol 2002, 37(9):1034-1041.

28. Cornelis P, Wei Q, Andrews SC, Vinckx T: Iron homeostasis and management of oxidative stress response in bacteria. Metallomics 2011, 3(6):540-549. Epub 2011 May 13.

29. Ott SJ, Musfeldt M, Ullmann U, Hampe J, Schreiber S: Quantification of intestinal bacterial populations by real-time PCR with a universal primer set and minor groove binder probes: a global approach to the enteric flora. J Clin Microbiol 2004, 42(6):2566-2572.

30. Garénaux A, Caza M, Dozois CM: The Ins and Outs of siderophore mediated iron uptake by extra-intestinal pathogenic Escherichia coli. Vet Microbiol 2011, 153(1-2):89-98. 
31. Thomazini CM, Samegima DA, Rodrigues MA, Victoria CR, Rodrigues J: High prevalence of aggregative adherent Escherichia coli strains in the mucosa-associated microbiota of patients with inflammatory bowel diseases. Int J Med Microbiol 2011, 301(6):475-479.

32. Andrews SC, Robinson AK, Rodríguez-Quiñones F: Bacterial iron homeostasis. FEMS Microbiol Rev 2003, 27(2-3):215-237.

33. Westendorf AM, Gunzer F, Deppenmeier S, Tapadar D, Hunger JK, Schmidt MA, Buer J, Bruder D: Intestinal immunity of Escherichia coli NISSLE 1917: a safe carrier for therapeutic molecules. FEMS Immunol Med Microbiol 2005, 43(3):373-384.

doi:10.1186/1471-230X-13-61

Cite this article as: Pilarczyk-Zurek et al.: Possible role of Escherichia coli in propagation and perpetuation of chronic inflammation in ulcerative colitis. BMC Gastroenterology 2013 13:61.

\section{Submit your next manuscript to BioMed Central and take full advantage of:}

- Convenient online submission

- Thorough peer review

- No space constraints or color figure charges

- Immediate publication on acceptance

- Inclusion in PubMed, CAS, Scopus and Google Scholar

- Research which is freely available for redistribution 